\title{
IMPACT OF ORAL HEALTH AND HEALTH BEHAVIOURS ON MOOD BEFORE A DENTAL VISIT
}

\author{
Katarzyna Białoszewska', Magdalena Łazarewicz², Stanisław Wójtowicz², Artur Z. Białoszewski³, Krzysztof Owczarek², \\ Dorota Olczak-Kowalczyk ${ }^{1}$
}

'Department of Paediatric Dentistry, Denistry Institute, Medical University of Warsaw, Poland

2Department of Medical Psychology and Medical Communication, Medical University of Warsaw, Poland

${ }^{3}$ Department of Prevention of Environmental Hazards and Allergology, Medical University of Warsaw, Poland

\begin{abstract}
INTRODUCTION: The literature describes relationships between negative emotions arising in connection with a dental appointment. Emotional processes and states thus represent factors that can considerably influence human health and oral health.

ОвJестіVEs: The aim of this study was to determine factors related to one's mood before visiting a dental office. MATERIAL AND Methods: Seventy-eight first-time dental patients ( 40 females, 38 males; Mage = 40.7, SD = 14.4) participated in the study. The participants completed a questionnaire consisting of a demographic data questionnaire, statements measuring subjective oral health, hygiene, and patients' knowledge about the oral cavity, and standardised research tools: the Mood Adjective Checklist (UMACL) and the Health Behaviour Questionnaire (HBI), prior to a dental visit. The DMFT index (DT - mean number of decayed teeth, MT - mean number of missing teeth, FT - mean number of filled teeth), Dental Treatment Index (DTI), and Approximal Plaque Index (API) were assessed during a clinical examination.

RESULTs: Hedonic tone (HT) was significantly related to number of filled teeth (FT) ( $p=0.036)$, subjective oral hygiene $(p<0.02)$, and level of knowledge about the oral cavity $(p<0.01)$. There was a significant correlation between HT and the HBI global score $(p<0.02)$ and Health practices $(p<0.01)$. Energetic arousal (EA) was related to the level of education $(p<0.04)$ and subjective factors influencing mood before the visit.

ConcLusions: The study shows that the factors that affect one's mood before a dental visit comprise education, oral health and hygiene, and health behaviours.
\end{abstract}

KEY wORDs: Poland, oral health, mood, dentist, health behaviours.

J Stoma 2019; 72, 2: 77-82

DOI: https://doi.org/10.5114/jos.2019.86987

\section{INTRODUCTION}

Mood refers to a subjective emotional state that adds affective colouring to everything around us [1]. The conceptual scope of mood is broader than that of emotions. The two concepts are distinguished by the intensity of experience, with emotions being associated with greater energy expenditure and duration. Also, unlike mood, emotions have an object, which means that it is difficult to identify a specific stimulus or addressee that has produced a particular mood [26].

There are a number of definitions and theories regarding the structure of mood. Larsen and Deiner (1992) gravitate towards a bipolar construct involving two bi-
JOURNAL OF STOMATOLOGY CZASOPISMO STOMATOLOGICZNE
ADDRESS FOR CORRESPONDENCE: Artur Z. Białoszewski,

Department of Prevention of Environmental Hazards and Allergology, Medical University of Warsaw, 1a Banacha St., 02-091 Warsaw, Poland, e-mail: artur.bialoszewski@gmail.com

ReCeIved: 27.03.2019 • ACCePted: 04.06.2019 • Published: 19.07.2019 
polar dimensions, namely hedonic (pleasure-displeasure) and that of arousal (high-low) [17]. Empirical data have led to the development of a three-dimensional model of mood involving the following three correlated factors: Hedonic tone (HT; pleasure-displeasure), Tense arousal (TA; tension-relaxation), and Energetic arousal (EA; energy-tiredness) [24]. TA can be described as anxiogenic, while EA can be defined as the energy to act [9].

Larsen [18] states that mood is a basic marker of an individual's well-being and mental health. Mood depends on external situations and internal factors (body function, physiological indicators, biological rhythm) $[9,23]$. Mood regulation is a fundamental process of affective functioning that involves the modelling or sustenance of a mood experienced by an individual with particular processes and behaviours [10].

Emotional processes and states thus represent factors that can considerably influence human health and quality of life. The association between mood and health can be analysed in various planes, with mood as an intermediary, cause, or result of disease. Various disorders can produce increased anxiety, tension or depression, which may influence the individual's acceptance of their ill health, adherence, and health behaviours [4].

The literature describes relationships between negative emotions arising in connection with a dental appointment on the one hand and the general level of anxiety and the presence of specific phobias, mood disorders, or evidence of distress on the other [3]. In one of very few studies of the relation between dental anxiety, mood, and general anxiety, Hakeberg et al. [11] demonstrated a statistically significant effect of hedonic tone on dental anxiety, with low mood levels predicting a high level of anxiety related to dental treatment. The authors also stress that many factors affecting treatment-related emotions are yet to be discovered.

An individual's emotional state together with such factors as physical health, health behaviours, and sociodemographic characteristics may influence the cognitive process, resulting in a subjective assessment of oral health [5]. Kaplan and Baron-Epel [15] stress that assessment criteria and the reference point as well as the cognitive processes involved in making a subjective assessment of one's oral health are not sufficiently documented.

\section{OBJECTIVES}

The aim of this study was to determine what factors are associated with mood before a dental visit.

\section{MATERIAL AND METHODS}

The study enrolled 150 patients of medicodental clinics from around Warsaw and its environs. Following analysis of exclusion criteria (confirmed mental disability, uncooperative patients, mental diseases and disorders, completely edentulous patients), the dataset for statistical analyses was ultimately made up of data from 78 participants $(\mathrm{F}=40, \mathrm{M}=38)$, aged $18-76$ years $(\mathrm{M}=40.65, \mathrm{SD}=14.4)$.

While awaiting their dental appointment in a waiting room, the participants were asked, following provision of informed consent to participate, to complete an anonymous questionnaire comprising an original part (including self-assessment of the participant's oral health and hygiene and knowledge about oral hygiene, and patient-reported factors affecting their mood before the visit) and a set of standardised research instruments for studying mood and health behaviours. This was followed by a clinical examination conducted by trained and calibrated investigators using a dental mirror and a 621 periodontal probe to assess the patients' oral health and hygiene. Consent to conduct the study was granted by the Ethical Review Board of the Medical University of Warsaw (KB/73/2013).

\section{RESEARCH INSTRUMENTS}

Mood was assessed using the UMACL Adjective Mood Rating Scale, developed by Matthews, Jones, and Chamberlain and adapted for Polish by Goryńska [9]. The theoretical basis for the design of the UMACL scale is the 89-item Mood Adjective Checklist (MACL), developed by Sjoberg et al. [27]. The Polish version consists of 29 adjectives describing the current mood of the subject. The scale uses four-way responses (definitely; rather; rather not; definitely not). UMACL findings include analysis of three scales of mood: HT, TA, and EA. Cronbach's a reliability coefficient for the UMACL scale ranges between 0.71 and 0.90 [9].

UMACL can be used in research on mood dynamics controlled for natural or experimentally-induced stress. According to Sjoberg et al. [27], the MACL, which serves as the theoretical foundation for the UMACL scale, is a scientifically confirmed diagnostic tool that indicates subjects' emotional responses related to a dental appointment.

Participants were also asked to mark factors affecting their well-being before a dental visit (the dentist's approach, level of knowledge about dental procedures, previous experience, type of procedure, financial aspects, pain intensity).

The intensity of health behaviours was assessed with the Health Behaviour Inventory (HBI) by Juczyński [14]. This tool comprises 24 statements grouped into four categories: correct eating habits, preventive behaviours, health practices, and positive mental attitude. Subjects mark the frequency of engaging in particular health-related activities on a five-item scale where: 1 means hardly ever; 2 - rarely; 3 - from time to time; 4 - often; and 5 - almost always. The item scores are then added up to produce a Global Health Behaviour Intensity Index 
(24-120 points). The coefficient of reliability was 0.85 for the Global Health Behaviour Index and 0.60-0.65 for the individual subscales.

Oral health and hygiene was assessed in a clinical examination, which served to calculate the following indices: Approximal Plate Index (API), caries severity index (DMFT index: DT - mean number of decayed teeth, MT - mean number of missing teeth, FT - mean number of filled teeth), and a Dental Treatment Index (DTI).

Subjective oral health and hygiene and knowledge about oral hygiene were assessed by the participants on a scale ranging from 1 - very poor to 5 - excellent.

\section{STATISTICAL ANALYSES}

Statistical analyses of the study data were performed using the IBM SPPS statistical software package. Statistical reasoning was based on Pearson's $r$ correlation for quantitative data and Kendall tau correlation for non-parametric variables. The Kruskal-Wallis $\mathrm{H}$ test followed by the Mann-Whitney $U$ test (as a post-hoc test) were used to compare differences between groups. The level of statistical significance was set at $p \leq 0.05$.

\section{RESULTS}

\section{SOCIODEMOGRAPHIC CHARACTERISTICS}

There was a weak positive significant correlation between EA and the participants' level of education (tau $=0.187, p<0.04)$. At the same time, there was no statistically significant correlation with the remaining demographic characteristics (Table 1).

\section{SELF-REPORTED FACTORS AFFECTING WELL-BEING}

All UMACL mood scales were significantly affected by the participant-reported factors affecting well-being in the dental office, with $\mathrm{H}(5)=11.741, p<0.04$ for TA, $\mathrm{H}(5)=16.201, p<0.006$ for EA, and $\mathrm{H}(5)=12.537$, $p<0.028$ for HT. Mann-Whitney tests were used to follow up this finding (Table 2).

Patients who indicated knowledge about dental procedures as a factor affecting their well-being had higher scores on TA than those who indicated approach of the dentist $(\mathrm{U}=13, p<0.003)$, previous experience $(U=4, p<0.03)$, or type of procedure $(\mathrm{U}=12.5, p<0.02)$. Additionally, patients reporting feeling pain as a factor affecting their well-being had higher scores on TA than patients reporting approach of the dentist as such a factor $(U=47, p<0.05)$.

Significantly lower EA scores were noted for patients who indicated knowledge about dental procedures than for all other patients (all $p<0.05$ ). Also, patients reporting feeling pain as a factor affecting their well-being had
TABLE 1. Results of Kendall's tau-b analysis of correlations between mood scales and the level of education

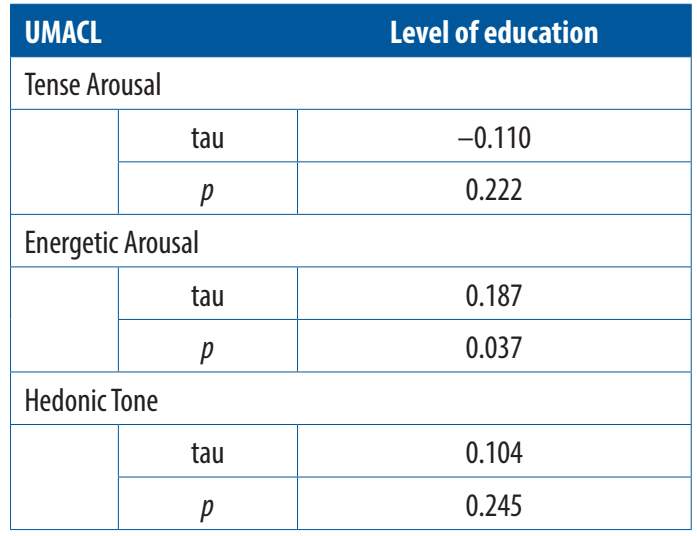

lower scores on EA than patients reporting approach of the dentist $(U=36, p<0.01)$ or type of procedure $(\mathrm{U}=15, p<0.003)$ as such a factor.

With regard to HT, patients who indicated knowledge about dental procedures as a factor affecting their well-being had significantly lower scores than those who indicated approach of the dentist $(\mathrm{U}=17, p<0.07)$ or type of procedure ( $U=8, p<0.005)$. Also, patients reporting feeling pain as a factor affecting their well-being had lower scores on HT than those reporting type of procedure as such a factor $(\mathrm{U}=26.5, p<0.03)$.

\section{ORAL HEALTH AND HYGIENE (TABLES 3 AND 4)}

HT was significantly associated with the mean number of filled teeth $(r=0.172, p=0.036)$. There were no statistically significant associations with any other components of the DMFT index or API.

Correlation analyses revealed a statistically significant correlation between HT and subjective assessment of oral hygiene (tau $=0.20 ; p<0.02$ ) and patients' knowledge $($ tau $=0.22 ; p<0.01)$. No significant correlations were noted with any other factors.

\section{HEALTH BEHAVIOURS}

Data correlation analysis revealed a statistically significant association between HT and the Global Health Behaviour Index $(r=0.257, p<0.02)$ and Health Practices $(r=0.291, p<0.006)$. In both cases, higher HT was associated with higher scores (Table 5).

\section{DISCUSSION}

The present study aimed to determine factors affecting mood before a dental appointment. Such factors in our study comprised education, health and oral hygiene status, health behaviours, and self-reported 
TABLE 2. Comparison of UMACL scales in subgroups selected with regard to self-reported factors affecting well-being in the dental office (Kruskall-Wallis test and Mann-Whitney post-hoc test)

\begin{tabular}{|c|c|c|c|c|c|}
\hline Factors affecting well-being & $n$ & Mean rank & H & $p$ & Mann-Whitney $\boldsymbol{U}$ test \\
\hline \multicolumn{6}{|l|}{ Tense arousal } \\
\hline 1 & 26 & 31.65 & \multirow[t]{6}{*}{11.741} & \multirow[t]{6}{*}{0.039} & $1<6$ \\
\hline 2 & 5 & 63.60 & & & $2>1,3 \& 4$ \\
\hline 3 & 7 & 38.14 & & & \\
\hline 4 & 17 & 35.88 & & & \\
\hline 5 & 15 & 41.50 & & & \\
\hline 6 & 7 & 51.79 & & & \\
\hline \multicolumn{6}{|l|}{ Energetic arousal } \\
\hline 1 & 26 & 43.12 & \multirow[t]{6}{*}{16.201} & \multirow[t]{6}{*}{0.006} & $2<1,3,4,5 \& 6$ \\
\hline 2 & 5 & 8.30 & & & $6<1 \& 4$ \\
\hline 3 & 7 & 41.43 & & & \\
\hline 4 & 17 & 45.88 & & & \\
\hline 5 & 15 & 41.03 & & & \\
\hline 6 & 7 & 22.14 & & & \\
\hline \multicolumn{6}{|l|}{ Hedonic tone } \\
\hline 1 & 26 & 43.35 & \multirow[t]{6}{*}{12.537} & \multirow[t]{6}{*}{0.028} & $2<1 \& 4$ \\
\hline 2 & 5 & 14.30 & & & $4>6$ \\
\hline 3 & 7 & 38.71 & & & \\
\hline 4 & 17 & 48.41 & & & \\
\hline 5 & 15 & 34.33 & & & \\
\hline 6 & 7 & 27.93 & & & \\
\hline
\end{tabular}

Factors affecting well-being: 1. Approach of the dentist, 2. Knowledge about dental procedures, 3. Previous experience, 4. Type of procedure, 5. Financial aspects, 6. Feeling pain.

TABLE 3. Results of Pearson's $r$ analysis of correlations between objective oral health (DMFT and API) and UMACL scores

\begin{tabular}{|c|c|c|c|c|c|}
\hline & DT & MT & FT & DMFT & API \\
\hline Tense ar & & & & & \\
\hline$r$ & 0.010 & 0.066 & -0.070 & 0.005 & -0.059 \\
\hline$p$ & 0.902 & 0.427 & 0.396 & 0.955 & 0.500 \\
\hline Energeti & rousal & & & & \\
\hline$r$ & -0.091 & 0.049 & 0.050 & 0.014 & 0.043 \\
\hline$p$ & 0.280 & 0.556 & 0.545 & 0.866 & 0.622 \\
\hline Hedonic & & & & & \\
\hline$r$ & -0.153 & -0.035 & 0.172 & 0.021 & -0.003 \\
\hline$p$ & 0.068 & 0.675 & 0.036 & 0.794 & 0.969 \\
\hline
\end{tabular}

DMFT index, and its components DT - decaying teeth, MT - missing teeth, FT - filled teeth, API - Approximal Plaque Index

factors affecting well-being (knowledge about dental procedures, type of procedure, presence of pain).

Educating patients about dental procedures and tailoring information presented to the specific needs of individual patients may change beliefs and eradicate preju-
TABLE 4. Results of Kendall's tau-b analysis of correlations between mood scales and subjective health status, oral hygiene level, and knowledge about oral cavity

\begin{tabular}{|c|c|c|c|}
\hline & Oral hygiene & Oral health & Knowledge \\
\hline \multicolumn{4}{|c|}{ Tense arousal } \\
\hline tau & -0.127 & 0.027 & -0.010 \\
\hline$p$ & 0.155 & 0.757 & 0.909 \\
\hline \multicolumn{4}{|c|}{ Energetic arousal } \\
\hline tau & 0.060 & 0.072 & 0.110 \\
\hline$p$ & 0.502 & 0.417 & 0.219 \\
\hline \multicolumn{4}{|c|}{ Hedonic tone } \\
\hline tau & 0.202 & 0.142 & 0.224 \\
\hline$p$ & 0.023 & 0.110 & 0.012 \\
\hline
\end{tabular}

EA-Energetic Arousal, TA - Tense Arousal, HT - Hedonic Tone

dice, thus favourably influencing emotions surrounding dental treatment [29].

Our results indicate an association between hedonic tone (pleasure-displeasure dimension) and the mean number of filled teeth among the participants. Earlier 
TABLE 5. Pearson's r analysis of correlations between health behaviours and UMACL score Global score of HBI Proper eating habits Preventive behaviour Positive psychological attitude Health practices

\begin{tabular}{|c|c|c|c|c|c|}
\hline$r$ & -0.045 & 0.019 & 0.01 & -0.038 & -0.15 \\
\hline$p$ & 0.693 & 0.871 & 0.928 & 0.739 & 0.19 \\
\hline \multicolumn{6}{|c|}{ Energetic arousal } \\
\hline$r$ & 0.005 & 0.037 & -0.081 & -0.091 & 0.151 \\
\hline$p$ & 0.965 & 0.749 & 0.481 & 0.431 & 0.187 \\
\hline \multicolumn{6}{|c|}{ Hedonic tone } \\
\hline$r$ & 0.235 & 0.123 & 0.164 & 0.16 & 0.291 \\
\hline$p$ & 0.038 & 0.282 & 0.15 & 0.162 & 0.01 \\
\hline
\end{tabular}

clinical and epidemiological studies have shown that patients displaying negative treatment-related emotions suffer from a higher number of oral conditions $[1,7,21]$.

Pre-treatment anxiety level, in turn, correlates with the caries index $[6,8]$.

At the same time, an association between mood and the API was not noted. Miller et al. [25] found a positive correlation between the level of anxiety and the prevalence of periodontal disease. Kurer et al. [16] state that there is a significant positive correlation between depression and the severity of dental plaque.

Subjective oral hygiene and level of knowledge were associated with mood (HT) before a dental visit. At the same time, there was no correlation between mood and self-reported oral health. Locker et al. [22] suggest that there is an empirically confirmed association between self-reported poor overall health and inadequate self-reported oral health and that these two aspects may influence one another. According to Locker et al. [20, 22], self-assessment of oral health is an independent indicator of the level of self-esteem, psychological well-being, and satisfaction with life. Assuming that HT reflects self-satisfaction, satisfaction, or pleasure, the present results can be compared with the results of studies investigating the link between happiness and self-reported oral health, which confirm an association between physical and mental health and the level of happiness and a correlation between the level of happiness and self-reported health status [12, 19, 28].

Statistical analysis also revealed an association between Hedonic tone on the one hand and the Global Health Behaviour Index and Health practices on the other. Self-reported oral health is also influenced by mood, as confirmed by the present study. The results of Yoon et al. [30] show that the frequency of cleaning one's teeth is reflected in one's sense of independence and interest in caring about oral health on one's own. Such activities are positively correlated with happiness. This finding was also confirmed in a study that reported a strong association between cleaning teeth and satisfaction with life [13].
According to Benyamini et al. [2], oral health, patients' subjective perception of oral health, and encouraging patients to practise oral health behaviours are crucial elements of doctor-performed evaluation of overall health.

Analysis of our data revealed certain substantial limitations, including sample size and re-administration of the UMACL test immediately after a procedure or after some time. These limitations indicate a need to perform more extensive studies utilising the UMACL adjective mood rating scale and analysis of the self-assessment process.

\section{CONCLUSIONS}

Despite the limitations of the study and a need for more extensive studies of mood changes in the setting of dental treatment, the findings of the present study demonstrate an association between mood before a dental visit and oral health. Mood is associated with patient-reported factors, such as oral hygiene, and factors influencing well-being associated with dental treatment and with the intensity of health behaviours practised by the participants.

\section{CONFLICT OF INTEREST}

The authors declare no potential conflicts of interest with respect to the research, authorship, and/or publication of this article.

\section{References}

1. Basińska MA, Waraksa-Wiśniewska M, Andruszkiewicza A. Nastrój jako wyznacznik akceptacji choroby pacjentów dializowanych. Nefrologia i Dializoterapia Polska 2014; 18: 27-31.

2. Benyamini Y, Leventhal H, Leventhal EA. Self-rated oral health as an independent predictor of self-rated general health, self-esteem and life satisfaction. Soc Sci Med 2004; 59: 1109-1116.

3. Berggren U, Meynert G. Dental fear and avoidance: causes, symptoms, and consequences. J Am Dent Assoc 1984; 109: 247-251.

4. Borkowska E, Watts T, Welnman J. The relationship of health beliefs and psychological mood to patient adherence to oral hygiene behaviour. J Clin Periodontol 1998; 25: 187-193. 
5. Chen X, Naorungroj S, Douglas CE, Beck JD. Self-reported oral health and oral health behaviors in older adults in the last year of life. J Gerontol A Biol Sci Med Sci 2013; 68: 1310-1315.

6. Cohen ME. Dental anxiety and DMFS status: association within a US naval population versus differences between groups. Community Dent Oral Epidemiol 1985; 13: 75-78.

7. Cohen S, Fiske J, Newton J. The impact of dental anxiety on daily living. Br Dent J 2000; 189: 385-390.

8. Dobros K, Hajto-Bryk J, Wnęk A, Zarzecka J, Rzepka D. The level of dental anxiety and dental status in adult patients. J Int Oral Health 2014; 6: 11-14.

9. Goryńska E. Przymiotnikowa Skala Nastroju UMACL. Pracownia Testów Psychologicznych PTP, Warszawa 2005.

10. Gross JJ. The emerging field of emotion regulation: An integrative review. Review of General Psychology 1998; 2: 271-299.

11. Hakeberg M, Hägglin C, Berggren U, Carlsson SG. Structural relationships of dental anxiety, mood, and general anxiety. Acta Odontol Scan 2001; 59: 99-103.

12. Hirosaki M, Ishimoto Y, Kasahara Y, Konno A, Kimura Y, Fukutomi E, et al. Self-rated happiness is associated with functional ability, mood, quality of life and income, but not with medical condition in community-dwelling elderly in Japan. Geriatr Gerontol Int 2011; 11: 531-533.

13. Honkala S, Honkala E, Al-Sahli N. Do life- or school-satisfaction and self-esteem indicators explain the oral hygiene habits of schoolchildren? Community Dent Oral Epidemiol 2007; 35: 337-347.

14. Juczyński Z. Narzędzia pomiaru w promocji i psychologii zdrowia. Pracownia Testów Psychologicznych PTP, Warszawa 2012; 149-155.

15. Kaplan G, Baron-Epel O. What lies behind the subjective evaluation of health status? Soc Sci Med 2003; 56: 1669-1676.

16. Kurer JB, Watts TLP, Weinman J, Gower DB. Psychological mood of regular dental attenders in relation to oral hygiene behaviour and gingival health. J Clin Periodontol 2005; 22: 52-55.

17. Larsen RJ, Diener E. Problems and promises with the circumplex model of emotion. In: Clark MS (ed.). Review of personality and social psychology. Vol. 13. Newbury Park, CA: Sage; 1992. pp. 25-59.

18. Larsen RJ. Toward a Science of Mood Regulation. Psychol Inq 2000; 11: 129-141.

19. Lloyd K. Health-related quality of life and childrens happiness with their childcare. Child Care Health Dev 2011; 38: 244-250.

20. Locker D, Clarke M, Payne B. Self-perceived Oral Health Status, Psychological Well-being, and Life Satisfaction in an Older Adult Population. J Dent Res 2000; 79: 970-975.

21. Locker D, Liddell A. Clinical correlates of dental anxiety among older adults. Community Dent Oral Epidemiol 1992; 20: 372-375.

22. Locker D, Wexler E, Jokovic A. What do older adults global selfratings of oral health measure? J Public Health 2007; 65: 146-152.

23. Marszał-Wiśniewska M. Podejście transakcyjne $\mathrm{w}$ badaniach zaburzeń nastroju. In: Fajkowska-Stanik M, Drat-Ruszczak K, Marszał-Wiśniewska M (eds.). Pułapki metodologiczne w badaniach empirycznych z zakresu psychologii klinicznej. Academica, Warszawa 2008

24. Matthews G, Jones DM, Chamberlain AG. Refining the measurement of mood: The UWIST Mood Adjective Checklist. Br J Psychol 1990; 81: 17-42.

25. Miller SC, Thaller JL, Soberman A. The use of the Minnesota Multiphasic Personality Inventory as a diagnostic aid in periodontal disease - a preliminary report. J Periodontol 1956; 27: 44-46.

26. Nowicka M. Regulacja nastroju w lęku i depresji. Doniesienia z badań. Studia Psychologiczne 2012; 50: 43-60.

27. Sjoberg L, Svensson E, Persson LO. The measurement of mood. Scand J Psychol 1979; 20: 1-18.

28. Subramanian SV. Covariation in the socioeconomic determinants of self rated health and happiness: a multivariate multilevel analysis of individuals and communities in the USA. J Epidemiol Community 2005; 59: 664-669.

29. Yildirim TT. Evaluating the Relationship of Dental Fear with Dental Health Status and Awareness. J Clin Diagn Res 2016; 10 ZC105-109.
30. Yoon HS, Kim HY, Patton LL, Chun JH, Bae KH, Lee MO. Happiness, subjective and objective oral health status, and oral health behaviors among Korean elders. Community Dent Oral Epiedmiol 2013; 41: 459-465 